1.- América Latina hoy y el futuro de la educación, la política, lo social, lo económico, lo cultural, lo espiritual, y el humanismo

1.- Latin America today and the future of education, politics, social, economic, cultural, spiritual, and humanism

1.- América Latina hoje e o futuro da educação, a política, o social, o económico, o cultural, o espiritual, e o humanismo

1

\section{AMÉRICA LATINA HOY Y EL FUTURO DE LA EDUCACIÓN, LA POLÍTICA, LO SOCIAL, LO ECONÓMICO, LO CULTURA, LO ESPIRITUAL Y EL HUMANISMO}

Latin America today and the future of education, politics, social, economic, cultural, spiritual, and humanism

América Latina hoje e o futuro da educação, a política, o social, o económico, o cultural, o espiritual, e o humanismo

Carmen Helena Bustamante Guerrero

DOI: 10.51862/obsknow.n3a1

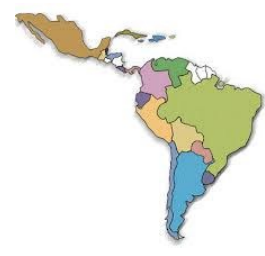

El presente artículo es una reflexión desde la perspectiva de la experiencia como doctora en Educación, desde hace diecinueve años. Lo que me permite realizar un análisis crítico de la Educación en América Latina y el estado juicioso de los procesos que de una u otra forma han sucedido, en el escenario de los países.

La educación es un fenómeno social de relevante importancia para la formación y el desarrollo del hombre. El destacado pedagogo catalán Octavi Fullat ha expresado: "el ser hombre es tener que educarse"1, para significar que no se pueden separar: antropos y educación.

1 Fullat, O. Filosofías de la educación, Pág.2. 
1.- América Latina hoy y el futuro de la educación, la política, lo social, lo económico, lo cultural, lo espiritual, y el humanismo

1.- Latin America today and the future of education, politics, social, economic, cultural, spiritual, and humanism

1.- América Latina hoje e o futuro da educação, a política, o social, o económico, o cultural, o espiritual, e o humanismo

Un antiguo aforismo cubano afirma que: "La educación empieza en la cuna y acaba en la tumba".2 Por lo tanto, la educación es más que un derecho y un deber de todos, es una necesidad humana.

El ser humano se educa por diferentes representaciones que posee la sociedad, las que han ido formándose y desarrollándose a lo largo de la historia de la humanidad. La familia, la comunidad, los grupos sociales, la iglesia, la escuela, los medios de comunicación masiva son representaciones educativas. Todas esas instituciones, y en especial, la escuela, tienen la responsabilidad de contribuir a completar la formación del individuo. Por estas razones: Hombre, Cultura, Sociedad y Educación forman una unidad indisoluble.

José Martí expresó: "Educar es depositar en cada hombre toda la obra que le ha precedido: es hacer a cada hombre resumen del mundo viviente, hasta el día en que vive: es situarlo a nivel de su tiempo, para que flote sobre él y, no dejarlo debajo de su tiempo, con lo que no podrá salir a flote; es preparar al hombre para la vida".3 En esta definición está muy claro el triple sentido que tiene que poseer toda acción educativa: ofrecer la herencia cultural, hacer que el sujeto sea actor en el mundo en que vive y convertirlo en autor, en creador, para que no resulte un ser pasivo, que solo se apropia de la cultura precedente, sino que sea capaz de aportar también a la cultura y a la sociedad. En eso consiste su verdadera realización como ser humano.

Al seguir el razonamiento anteriormente expresado en relación con la significación de la educación para el progreso humano, entonces, se tiene que admitir que éste puede ser educado. Esto es posible, porque en la propia naturaleza del hombre existen condiciones, predisposiciones potencialidades para ese fin y para su auto educación. De ahí su educabilidad.

Ahora bien, hay que tener presente que entre la estructura escolar del hombre y las potencialidades del medio natural y social tiene que existir otro factor importante, intermediario entre la persona y el medio: ese es el educador. Sin una orientación conscientemente organizada y dirigida a un

2 José de la Luz: Aforismos, En: Selección de textos de José de la Luz y Caballero, Pág. 167.

3 Martí, José: Obras completas, t. 8, Pág. 281. 
1.- América Latina hoy y el futuro de la educación, la política, lo social, lo económico, lo cultural, lo espiritual, y el humanismo

1.- Latin America today and the future of education, politics, social, economic, cultural, spiritual, and humanism

1.- América Latina hoje e o futuro da educação, a política, o social, o económico, o cultural, o espiritual, e o humanismo

fin determinado no se puede producir una auténtica educación. Puede existir una de manera espontánea, pero ese proceso tiene que ser guiado, orientado de una manera muy especial para que logre sus mejores efectos. El carácter de guía del educador (padre, maestro) tiene que ser con gran tacto y flexibilidad, porque cada ser humano tiene una forma muy peculiar para apoderarse del conocimiento y operar con él.

En fin, el acto educativo es una obra de infinito amor. Solo se da, verdaderamente, entre sujetos. Por lo tanto, la educación es una categoría eterna de la sociedad y no cesa durante toda la vida del hombre.

La educación está condicionada por los factores macrosociales: economía, política, cultura, pero este principio no significa para nada la simple adaptación del hombre a la realidad. A su vez, como se modela en las siguientes relaciones, la educación es condicionante y determina el constante sentido del progreso -material y espiritual- que vive el ser humano, esto es, su trascendencia.

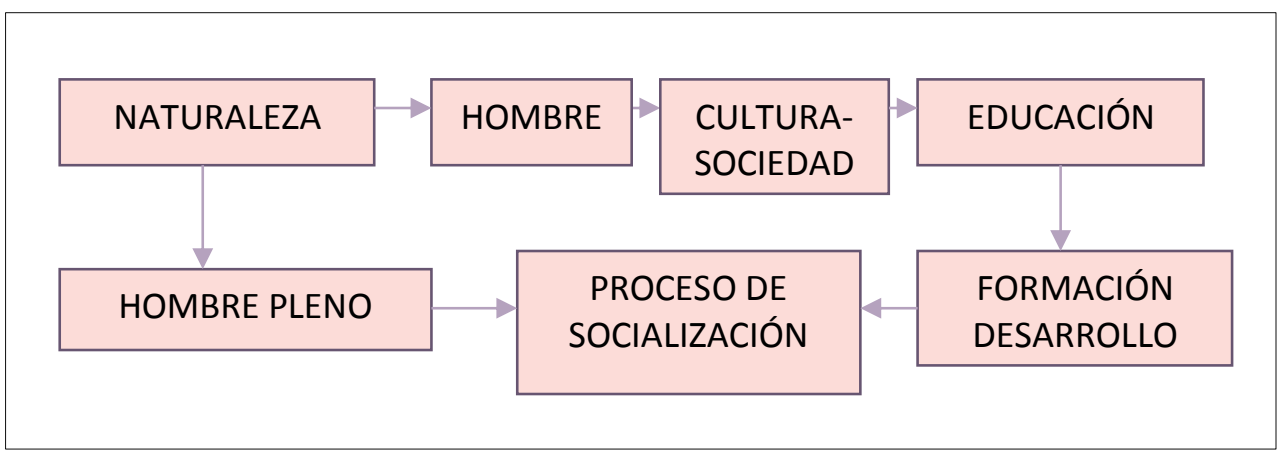

Este proceso se da en una unidad dialéctica y la hipertrofia de uno de los elementos en detrimento del otro, produce enfoques unilaterales y erróneos acerca del papel de la educación en el desarrollo social y humano.

El proceso educativo en el hombre, ya se dijo, no puede ser espontáneo, y tiene que llegar a todos. Ese principio, que parte desde Juan Amos Comenio: que es necesario dar "todo a todos", se convierte en la actualidad en una necesidad histórica. Es vital, pues, extender los servicios educativos a las poblaciones desfavorecidas, para que realmente se sientan que todos reciben la influencia de la correcta educación. Esa educación tiene que ser de calidad. No basta extender la cobertura, ésta ha de ser de calidad. ¿Qué 
1.- América Latina hoy y el futuro de la educación, la política, lo social, lo económico, lo cultural, lo espiritual, y el humanismo

1.- Latin America today and the future of education, politics, social, economic, cultural, spiritual, and humanism

1.- América Latina hoje e o futuro da educação, a política, o social, o económico, o cultural, o espiritual, e o humanismo

se dice con esto? Que la educación debe ser: integral, científica, desarrolladora de la personalidad, que los conocimientos y las habilidades adquiridos puedan ser usados por la persona que aprende.

Para nada sirven conocimientos fraccionados, incompletos y poco sólidos. Se estará, entonces, ofreciendo la apariencia que se está educando a todos, pero el resultado es débil y de poca utilidad. Este particular no se dice, en el sentido de que se esté pensando en el utilitarismo pragmático, ni mucho menos; se expresa por el hecho de que el producto terminal del proceso educativo, aunque este no acaba nunca, por lo menos el dirigido, tiene que dar al hombre los instrumentos, materiales y espirituales con los que ha de luchar en la vida.

En la actualidad se produce una contradicción, que trae concepciones erróneas. Esta polémica está en el sentido de que ¿se puede o no conciliar la masividad con la calidad? La respuesta es absolutamente afirmativa, pero de difícil comprensión por algunos tratadistas y políticos.

\section{¿Reforma, cambio o mejoramiento?}

Hoy se conoce cómo las transformaciones no ocurren a un mismo ritmo, en un mismo sentido, ni siempre de forma total sino a través de un complejo proceso de cambios cuantitativos y cualitativos capaces de sostener, sin embargo, en los objetos y fenómenos, la necesaria dinámica de estabilidad y transformación.

Una muestra de la complejidad de estos procesos en el plano social, son los acelerados cambios del mundo contemporáneo:

"Cambios, expresa la educadora argentina Inés Aguerrondo, en el orden político internacional, en los modelos socio económicos y en la globalización cada vez mayor de las economías. Cambios revolucionarios a nivel científico, tecnológico y en la forma de organización de la producción; en las pautas culturales y en el papel de los medios de comunicación masiva. Profundas modificaciones en las demandas que la población articula respecto a la educación. Transformaciones que también han exigido nueva 
1.- América Latina hoy y el futuro de la educación, la política, lo social, lo económico, lo cultural, lo espiritual, y el humanismo

1.- Latin America today and the future of education, politics, social, economic, cultural, spiritual, and humanism

1.- América Latina hoje e o futuro da educação, a política, o social, o económico, o cultural, o espiritual, e o humanismo

perspectivas desde los paradigmas teóricos y desde las categorías de análisis de la realidad social y en particular de la educación".4

La educación, como fenómeno social, dio muestras en el siglo XX de estos procesos de cambio, tal es el caso de las acciones promovidas como parte del movimiento reformista de la Nueva Educación, así como las políticas de reformas educativas implementadas desde la década del setenta en países desarrollados y en la América Latina quince a veinte años después.

Las concepciones acerca de la necesidad de cambios en la educación se dieron a lo largo de todo el siglo XX, a través de un lapso que se aceleró en las últimas décadas, sin embargo, ello no significa que exista consenso en todos los implicados en cuanto a qué, cómo y para qué cambiar y mucho menos la certeza en relación con el valor de los cambios efectuados.

Unido a lo antes planteado, el propio avance de las Ciencias de la Educación, particularmente en lo que se refiere a los resultados de las investigaciones sobre el proceso de enseñanza-aprendizaje, han puesto en evidencia la necesidad de promover cambios en las concepciones y prácticas predominantes en la dirección de este proceso, centradas esencialmente en el empeño de mejoramiento de la enseñanza, con cierto abandono del otro componente del proceso; el aprendizaje.

Las posibilidades de emprender los cambios que hoy se reclaman son inobjetables: los países han alcanzado en el orden cuantitativo los niveles más altos de toda su historia en indicadores de desarrollo educativo, lo que le permite concentrar todos sus esfuerzos en el empeño de llevar adelante transformaciones, orientadas a la elevación de la calidad de los servicios educativos y particularmente, en el mejoramiento acelerado del proceso de enseñanza-aprendizaje.

De esta manera, el cambio al que se aspira, debe estar orientado a la acrecentamiento de la calidad de la educación, incluida como parte de ella, una mayor pertinencia social del sistema educativo para las nuevas condiciones políticas y económicas en las que se desenvuelve la sociedad de hoy.

Cambio y calidad son entonces dos conceptos sobre los que debemos detenernos de manera particular, de manera que todos podamos entender

4 Aguerrondo, Inés. Et Al. (1993) Para qué sirve la escuela. Grupo Editorial Norma. Argentina. 
1.- América Latina hoy y el futuro de la educación, la política, lo social, lo económico, lo cultural, lo espiritual, y el humanismo

1.- Latin America today and the future of education, politics, social, economic, cultural, spiritual, and humanism

1.- América Latina hoje e o futuro da educação, a política, o social, o económico, o cultural, o espiritual, e o humanismo

la profundidad y alcance de ambos y sus implicaciones en nuestro accionar educativo concreto.

Para el siglo en que hemos vivido, el cambio ha sido la única constante; esto se reconoce así en el informe presentado por el Programa de Naciones Unidades para el Desarrollo (PNUD), bajo el título de "Educación: la Agenda del siglo XXI", donde además se afirma que "educar hoy es educar para el cambio", 5 lo que se traduce de manera directa en una reforma necesaria de los sistemas educativos, que se concreta, de acuerdo con el mencionado informe, en: "No el aprender por aprender, sino aprender a aprender. No la solución a los problemas, sino la capacidad de resolver problemas. No la repetición, que es cierta, sino la libertad, que es incierta. No el dogmatismo, sino la tolerancia. No la formación para el empleo, sino la formación para la empleabilidad. No la educación terminal, sino la educación permanente, la educación arte y parte de toda la vida".6

Para nuestra América Latina, el cambio en la educación se ha asumido desde la óptica de las modificaciones de los sistemas educativos, procurando actuar de modo simultáneo, sobre sus facetas administrativas, financieras, curriculares y pedagógicas, siendo sus objetivos fundamentales: a) el mejoramiento de la eficiencia del sistema en todas sus instancias, b) la adecuación del currículo a las exigencias de la globalización, c) responsabilizar a las madres y padres de familia y la comunidad con la gestión escolar y d) canalizar los subsidios hacia la población más necesitada.

De manera sintética, en el informe sobre la Agenda del siglo XXI, al hacer un balance de las reformas educativas en el área se dice textualmente: "EI panorama global, sin embargo, no parece muy alentador. Salvo algunas innovaciones que se destacan -precisamente porque son excepciones- la percepción más común entre observadores tiende a ser pesimista. Muchas reformas -o muy buena parte de las reformas- se quedan en los anaqueles de los ministerios o en los archivos de las oficinas de planeación. Otras muchas se desdibujan al pasar a la práctica o avanzan con lentitud exasperante. Raramente se llega a transformar la vida cotidiana de las

5 Educación: La agenda del Siglo XXI (1998). Hacia un desarrollo humano. PNUD. TM Editores, Colombia, p. XXX.

6 Educación: La agenda del Siglo XXI (1998). Hacia un desarrollo humano. PNUD. TM Editores, Colombia, p. XXX. 
1.- América Latina hoy y el futuro de la educación, la política, lo social, lo económico, lo cultural, lo espiritual, y el humanismo

1.- Latin America today and the future of education, politics, social, economic, cultural, spiritual, and humanism

1.- América Latina hoje e o futuro da educação, a política, o social, o económico, o cultural, o espiritual, e o humanismo

escuelas, a revitalizar las prácticas pedagógicas, a cambiar las rutinas burocráticas, a derrotar los intereses creados.

El hecho en sí no es una sorpresa. Las prácticas educativas están demasiado amarradas a la inercia y los faustos educativos son demasiado pesados para cambiarlos de la noche a la mañana".7

Para nuestro país, la esencia del cambio educativo, sin desconocer la necesidad de ajustes en las estructuras y funciones dentro del sistema para hacerlo corresponder cada vez más con las nuevas condiciones económicas y sociales, radica en la búsqueda de niveles superiores de calidad. Resultado, como ya antes señalamos, de haber logrado avances importantes en términos de cantidad: cobertura, escolarización, retención, infraestructura, recursos humanos, entre otros. ¿Cómo entender entonces el alcance y profundidad del cambio educativo orientado a la elevación de la calidad en nuestra realidad concreta?

Para responder a la pregunta anterior, considero oportuno precisar que, si de cambio en función de la elevación de la calidad de la educación se trata, entonces es necesario analizarlo en dos grandes dimensiones: el cambio como proceso y el cambio como resultado.

El cambio educativo como proceso supone una manera diferente de hacer las cosas, es transformar los modos de actuación de los miembros de la comunidad educativa, de manera que se correspondan con las nuevas exigencias del desarrollo económico, político y social, así como con los avances en el conocimiento, sobre el fenómeno educativo alcanzado por las Ciencias de la Educación.

El cambio como resultado se refiere a la resultante del tránsito que se logre, de la realidad educativa existente en un momento dado a aquella que se desea alcanzar, y que tiene como centro o aspiración esencial, la aproximación sucesiva al modelo de ser humano que demanda nuestro sistema social y a la transformación de las concepciones y actitudes de los miembros de la comunidad educativa sobre el fenómeno educativo y de la visión sobre la escuela, su funcionamiento interno y el papel en la comunidad.

De esta manera, el cambio educativo puede ser entendido como el "Proceso de transformación gradual e intencional de las concepciones, actitudes y prácticas de la comunidad educativa escolar, dirigido a promover

7 Educación: La Agenda del Siglo XXI. (1998). Op. Cit. P. 154. 
1.- América Latina hoy y el futuro de la educación, la política, lo social, lo económico, lo cultural, lo espiritual, y el humanismo

1.- Latin America today and the future of education, politics, social, economic, cultural, spiritual, and humanism

1.- América Latina hoje e o futuro da educação, a política, o social, o económico, o cultural, o espiritual, e o humanismo

una educación desarrolladora en correspondencia con el Modelo Genérico de las condiciones socio- históricas concretas."8

Como cualquier proceso, el cambio educativo tiene que estar sujeto a una dirección cuya intencionalidad esté orientada por los objetivos que se planteen alcanzar, en correspondencia con las condiciones históricoconcretas tanto en el plano macrosocial como en el micro, en este caso referido al aula, la escuela y la comunidad.

En su carácter de proceso y resultado, el cambio educativo supone la intervención de los miembros de la comunidad educativa en el doble carácter de sujetos y de objetos, es decir, como sujetos o actores de la evolución y como objetos de transformación en sí mismos, aunque conscientes y activos. En esto radica la contradicción principal que debe ser resuelta para el logro del cambio educativo: el salto depende de los sujetos y estos al mismo tiempo tienen que cambiar.

\section{Posiciones acerca de la calidad de la educación en América Latina}

Uno de los problemas de la teoría de la educación que más preocupa actualmente es que no contribuye, o lo hace débilmente, a la calidad de la educación.

La calidad educativa es un concepto complejo porque está referido a un fenómeno también complejo. Valorarla significa analizar el conjunto de cualidades que posee la educación, atendiendo a su carácter procesal, dinámico, multifactorial, social e históricamente determinado. La calidad de la educación implica una comparación de orden cualitativo y cuantitativo, consigo mismo y con los demás.

La calidad de la educación es percibida de distintas maneras:

1. Como algo que se exige pero que está muy alejado del quehacer escolar y su contexto, porque no se han tenido en cuenta las condiciones para alcanzarla; quiere decir que el modelo está por encima de las posibilidades reales,

8 Castellanos, D. y otros (2001). Hacia una concepción del aprendizaje desarrollador, Colección Proyectos, ISP “E. J. Varona”, p.14. 
1.- América Latina hoy y el futuro de la educación, la política, lo social, lo económico, lo cultural, lo espiritual, y el humanismo

1.- Latin America today and the future of education, politics, social, economic, cultural, spiritual, and humanism

1.- América Latina hoje e o futuro da educação, a política, o social, o económico, o cultural, o espiritual, e o humanismo

2. vinculada solamente a aspectos puntuales o superficiales, dentro del proceso educativo; significa una injusta valoración de la calidad que debe lograrse,

3. como una responsabilidad del maestro; dependerá de la interpretación personal, de las posibilidades y deseos individuales de cada cual.

El concepto calidad educativa debe ser interiorizado como resultado de un profundo proceso de reflexión, en el que se revele su alcance, contenido y profundidad, y se exprese o concrete en la práctica cotidiana de las instituciones escolares.

De manera general la calidad educativa se puede entender como excepción, perfección, aptitud para un propósito prefijado, valor agregado o como transformación.

Calidad educativa es, en última instancia, lograr que todos los estudiantes independientemente de sus condiciones personales, sociales y culturales aprendan lo que tienen que aprender, en el momento en que lo deban aprender y desarrollen los valores y las competencias necesarias.

Para todos los países, elevar la calidad de la educación se ha convertido en un grito de angustia existencial. Se habla constantemente de ¿qué es calidad de la educación? y ¿cómo llegar a ella? La solución de este problema se aprecia como una necesidad imperiosa de nuestro tiempo.

Al respecto el Doctor Carlos Rojas, Investigador del Centro de Estudios Educacionales de la Universidad Pedagógica "Enrique José Varona" al referirse a las preguntas antes formuladas expresa: "Cuando el objeto está referido a la educación, entonces ya no resulta tan evidente u objetiva la calidad, por cuanto la percepción que de ella se tiene es muy dependiente de factores objetivos y de un nivel relativamente bajo en el desarrollo de las ciencias que tributan a su caracterización. Es decir, a la pregunta sobre ¿qué es una educación de calidad?, pueden darse tantas respuestas como sujetos estén implicados o participen de ella y de los contextos desde los cuales se formula la respuesta", y a continuación señala: "La respuesta es más difícil aún por el hecho de que en la educación no solamente hablamos 
1.- América Latina hoy y el futuro de la educación, la política, lo social, lo económico, lo cultural, lo espiritual, y el humanismo

1.- Latin America today and the future of education, politics, social, economic, cultural, spiritual, and humanism

1.- América Latina hoje e o futuro da educação, a política, o social, o económico, o cultural, o espiritual, e o humanismo

de un producto, un resultado; es fundamental tener en cuenta el proceso en sí mismo mediante el cual se llega a ese producto, a ese resultado" 9

La Organización de Estados Iberoamericano (OEI), no por casualidad le dedicó al tema -enero-abril de 1996- una de sus revistas especializadas. En ella, aparecen diferentes criterios acerca de la calidad de la educación y de su evaluación, pero en casi todos los casos, la definición se hace al margen del fenómeno de la masividad de la educación. Si incluyen este asunto, es para decir, que es necesario controlar la masividad para garantizar la calidad, pues la teoría al uso no puede enfrentar ese hecho inusitado y necesario de nuestro tiempo.

El reto de la teoría educativa está en enfrentar y en resolver la contradicción entre la masividad y la calidad de la educación. La teoría tiene que enfrentar ese problema desde la óptica misma de la abundancia. La vía más efectiva, es llevar a los profesores, el espíritu científico. Que reconozcan y sepan resolver las dificultades educativas que a diario se presenten en el aula, con el uso de métodos científicos para ello.

La investigación científica desde la escuela, debe ser el arma más poderosa para elevar la calidad del aprendizaje. El profesor no tendrá que esperar a que las soluciones les lleguen desde otras instancias o fuera de su municipio, es decir, de su contexto.10 Además, el uso adecuado de las tecnologías al servicio de la educación, en la actualidad constituye un elemento facilitador para acelerar el proceso del aprendizaje.

Nadie mejor que el profesor para resolver los problemas de su propia práctica pedagógica. Esto le dará un significativo protagonismo en el proceso al docente. Por supuesto, que le exige que se prepare convenientemente para asumir esa función.

Además, la investigación científico-educativa tiene que salirse de la campana de cristal de las instituciones especializadas y situarse, con todo su rigor, a disposición del profesor, de una manera sencilla y natural. Sólo así aparecerán las soluciones en la práctica educativa, que se convertirán después, en sustentadoras de la teoría.

9 Rojas. C. y D. Torres (2001). "El cambio educativo: una concepción avanzada para el mejoramiento de la calidad de la educación". En: Revista Varona, Ciudad de La Habana. No. 33, (julio-diciembre), pág. 33.

10 En Colombia se trabaja, en algunos sectores, por la pedagogía local. 
1.- América Latina hoy y el futuro de la educación, la política, lo social, lo económico, lo cultural, lo espiritual, y el humanismo

1.- Latin America today and the future of education, politics, social, economic, cultural, spiritual, and humanism

1.- América Latina hoje e o futuro da educação, a política, o social, o económico, o cultural, o espiritual, e o humanismo

La misma teoría, entonces, ajustará sus conceptos o los cambiará y volverá a reorientarse a la práctica. Es ese el ciclo vital y único para lograr que la ciencia pedagógica y sus ciencias auxiliares asuman las tareas de la calidad desde la propia masividad. Gran reto, pero posible y necesario.

\section{Diferentes tendencias}

El interés por la universalización de la enseñanza en la mayoría de los países de América Latina y la lucha por hacerla realidad, comenzó realmente a fines del s. XIX. Este propósito se ha ido ampliando y fortaleciendo en el s. XX y lo que va del s. XXI. El proceso ha pasado por diferentes etapas, que ofrecen soluciones teóricas al problema de la extensión de los servicios educativos y enfrentar el delicado asunto de la calidad.

En la década de los años sesenta del s. XX, los gobiernos de los países latinoamericanos concentraron sus esfuerzos, en materia de política educativa, en tratar de ampliar el posible acceso a la educación de las niñas, los niños, adolescentes y jóvenes. Esta posición estaba sustentada por los criterios del desarrollismo de la Comisión Económica para América Latina y el Caribe (CEPAL), que consideraba que, con solo elevar la cobertura de los servicios educativos, se resolverían los graves problemas sociales que existían. Este hecho se da por hipertrofiar una de las condiciones de la educación, como se dijo anteriormente. Por lo tanto, se esperaba que se resolvieran los males sociales de entonces, y que, mediante el acceso de los ciudadanos a la cultura, la economía se fortalecería.

El aumento relativo de la escolarización de los países de la región, no se tradujo en la elevación de la calidad de la educación a los niveles esperados ni la solución de los problemas socioeconómicos que se pensaban resolver.

Puede afirmarse que el criterio desarrollista fracasó en realidad. Es importante recordar que "de 1990 a 1998 el número de niños sin escolarización en América Latina se bajó de 127 a 113 millones y que el índice de alfabetización dar votos alcanzados solamente el $85 \%$ entre los hombres y de $74 \%$ entre las mujeres". 11

11 La Educación para Todos. Carpeta de Información. En: Un objetivo a nuestro alcance, p. 1. 
1.- América Latina hoy y el futuro de la educación, la política, lo social, lo económico, lo cultural, lo espiritual, y el humanismo

1.- Latin America today and the future of education, politics, social, economic, cultural, spiritual, and humanism

1.- América Latina hoje e o futuro da educação, a política, o social, o económico, o cultural, o espiritual, e o humanismo

Hay que reconocer que entre 1960 y 1980, o sea, en veinte años, se hizo realidad la expansión de la enseñanza en el nivel primario, pero sin una profunda preocupación por la calidad de la educación que se ofrecía. Esto quiere decir que no existía una teoría bien organizada para medir la calidad de la educación. Lo que se hacía y cómo se hacía era valorado con criterios puramente empíricos y positivistas de cada país. Había una gran influencia del funcionalismo deweyano en las concepciones acerca de la calidad de la educación.

En la década los años ochenta y noventa, se produjo un importante cambio en el interés por la educación en el mundo. En esas décadas la preocupación no estaba solo centrada en elevar la escolarización, sino en ofrecer una educación con calidad. Este particular interés permanece en el nuevo milenio.

En las conferencias de los ministros educación y la Organización de las Naciones Unidas, para la Educación, la Ciencia y la Cultura (UNESCO), en los años de la década del sesenta y del setenta, se impulsan las metas relativas a la calidad de la educación para todos, que fueron asumidas en las conferencias de Quito y en la Declaración Mundial de Jomtiem en el año de 1990.

Hoy por hoy existe el criterio en relación con la necesidad, no solo de elevar la escolarización, sino que, además, en esas escuelas se incorporan, de manera efectiva, los conocimientos, las habilidades, los hábitos, las capacidades, para que de esa manera puedan participar de la sociedad con éxito.

Las metas educativas actuales, al ser diferentes y superiores a las fijadas en décadas anteriores, presuponen la identificación y la puesta en práctica de políticas educativas que tenga en cuenta y le den importancia a los factores escolares y extraescolares que tienen una probada asociación con el desarrollo individual de los estudiantes. Estas consideraciones han traído un cambio también en la concepción de cómo lograr la calidad de la educación y de cómo evaluarla. Hoy se enfrenta el problema desde una óptica más integral y humanista.

Durante décadas el sector educativo trabajó bajo el supuesto de que la educación estaba simplemente, condicionada por las esferas macrosociales: condiciones socioeconómicas y culturales externas al sistema educativo, y que de ellas dependería el éxito de los escolares, y que poco podía hacerse al interior de la escuela misma, para evitar o 
1.- América Latina hoy y el futuro de la educación, la política, lo social, lo económico, lo cultural, lo espiritual, y el humanismo

1.- Latin America today and the future of education, politics, social, economic, cultural, spiritual, and humanism

1.- América Latina hoje e o futuro da educação, a política, o social, o económico, o cultural, o espiritual, e o humanismo

suavizar los problemas de la calidad de la educación. Este criterio resultó ser fuertemente determinista.

Entre los años de 1995 y 1997, se desarrolló el Primer estudio Internacional Comparativo del Laboratorio Latinoamericano de Evaluación de la Calidad de la Educación, que agrupó a 17 países Latinoamericanos. En el informe sobre los resultados del estudio se señala que: "se comprueba que los " factores vinculados a la escuela"- insumo y procesos, son los responsables de cerca de dos tercios de la gran variación en el rendimiento de los estudiantes".12.El resultado de la investigación antes referida posibilitó encontrar una arista del problema de la calidad, que no había sido convenientemente revelada aún, se trata del hecho que había que profundizar en el proceso docente educativo, que tiene lugar en las instituciones escolares y en sus aulas.

Por primera vez, se comenzó a afirmar, más allá de la intuición, que al clima del aula es necesario darle la significación que requiere, en este estudio se materializa lo expresado, en 109 de los 140 puntos de la escala utilizada para medir el rendimiento escolar de los estudiantes en Lenguaje y Matemática, lo que alude indiscutiblemente a la importancia de la gestión educativa del profesor, para lograr el desarrollo esperado en los estudiantes.

Puede decirse que, en el último decenio del siglo pasado los sistemas educativos llegaron a priorizar los esfuerzos encaminados para el mejoramiento de la calidad de la educación y, en ese interés, se ha identificado a la actividad profesional del profesor, como un aspecto determinante para el salto cualitativo de la gestión escolar y sus resultados, en correspondencia con la necesidad de todas las sociedades.

Se ha llegado al consenso de que el fracaso en el éxito de todo sistema educativo depende esencialmente de la calidad del trabajo profesional del pedagogo.

Además, se está de acuerdo con el especialista cubano en materia de calidad de la educación, el doctor Héctor Valdés Veloz, quien afirma, en su tesis para la obtención del grado científico de Doctor en Ciencias Pedagógicas, que: "Podrán perfeccionarse los planes de estudio,

12 Cassasus, Juan y otros (2000): Primer estudio comparativo sobre Lenguaje y Matemática y factores asociados, Editorial Andrews, Chile, pág. 13. 
1.- América Latina hoy y el futuro de la educación, la política, lo social, lo económico, lo cultural, lo espiritual, y el humanismo

1.- Latin America today and the future of education, politics, social, economic, cultural, spiritual, and humanism

1.- América Latina hoje e o futuro da educação, a política, o social, o económico, o cultural, o espiritual, e o humanismo

programas, textos escolares; construirse magníficas instalaciones; obtenerse excelentes y modernos medios de enseñanza, pero sin profesores eficientes no podrá tener lugar el perfeccionamiento real de la educación".13

Esta es una gran verdad, pero no se pretende retroceder al magistrocentrismo de la tradicional escuela latinoamericana, sino a un profesor de calidad que junto a los estudiantes pueda enfrentar el proceso enseñanza -aprendizaje de una manera activa y creativa.

Existen, por lo tanto, dos grandes momentos en el desarrollo del proceso de la calidad de la educación:

1. Un momento de desinterés o de no preocupación oficial y organizada por la calidad de la educación, por los resultados, esto quiere decir, por la calidad en la formación y el desarrollo de la personalidad de los estudiantes. Este es un proceso que va desde los años de los sesenta, hasta mediados los ochenta. En este momento sólo hubo preocupación por la extensión del proceso educativo, o sea, por ampliar la escolarización. No quiere decirse con esto, que no existiese preocupación individual, pero las Políticas Educativas no contemplaban este particular.

2. Un momento, después de mediados de los ochenta, que llega hasta la actualidad, en que predomina una concepción humanista de la educación, en la que se toma conciencia plena de que la calidad de la educación había que buscarla, no sólo en el crecimiento de las estadísticas de la incorporación de los estudiantes a las aulas, sino que estuviesen, de una manera integral, bien preparados para la vida.

El momento más significativo lo constituyó la investigación comparada de 17 países, de Latinoamérica a la que se ha hecho referencia, que sus resultados dieron con la clave de los problemas esenciales de la calidad, que estaban en los factores asociados a la educación y en el interior del aula, en el que el profesor y el estudiante son los verdaderos protagonistas de ese proceso.

13Valdés, Héctor: un sistema de evaluación del desempeño profesional del docente de escuela básica cubana. Tesis para optar por el grado científico de Doctor en Ciencias Pedagógicas, pág. 4. 
1.- América Latina hoy y el futuro de la educación, la política, lo social, lo económico, lo cultural, lo espiritual, y el humanismo

1.- Latin America today and the future of education, politics, social, economic, cultural, spiritual, and humanism

1.- América Latina hoje e o futuro da educação, a política, o social, o económico, o cultural, o espiritual, e o humanismo

Ese descubrimiento científico ha hecho girar las investigaciones educativas y sus intereses a la búsqueda de las verdaderas razones de la insuficiente calidad del proceso de enseñanza-aprendizaje.

Se ha puesto, desde entonces, mucho énfasis en la preparación y superación del profesorado y de la evaluación de la calidad de los educadores mismos. Si no se transforman los educadores, la educación no se transformará. Como afirmó Carlos Marx: el profesor debe ser educado.

Se puede afirmar que partir del año de 1997 hay más conciencia en los países latinoamericanos, acerca de ¿cómo enfrentar la masividad de la educación que se proyecta, sin perder la necesaria e indispensable calidad?

En resumen los criterios de la calidad han tenido diferentes enfoques que van desde el utilitarismo pragmático, que a partir la década de los años cincuenta- posguerra -invadió teóricamente los países del área a posiciones que se pueden calificar de humanistas, y que comprende el llamado humanismo crítico, seguidor de la segunda generación de la escuela de Frankfurt, con Habermas a la cabeza y que orienta hoy por hoy a muchas políticas educativas en el área, al humanismo cristiano, seguido de la filosofía personalista, que en Colombia tiene sus más legítimos representantes en: J.M. Burgos Velasco, J. Garzón Pascagaza y el humanismo marxista representado por la escuela vigosquiana de corte histórico culturalista.

\section{La calidad de la actividad profesional del profesor}

A fines de la década de los noventa del s. XX se llegó a la conclusión que para que hubiera "calidad" en el proceso educativo, era necesario garantizar primero, la calidad de la actividad profesional de los profesores. ¿En qué estado se encontraba este particular?

A inicios del año 2002, se comenzó una investigación para conocer con la mayor exactitud posible el estado de la evaluación del desempeño de los profesores. Participaron en ella 14 países, que fueron: Argentina, Brasil, Bolivia, Colombia, Costa Rica, Cuba, El Salvador, Guatemala, México, Paraguay, Perú, República Dominicana y Uruguay. Se creó un llamado "grupo de interés" para esos fines y se aplicaron herramientas científicamente preparadas para dicha investigación. A grandes rasgos, las conclusiones fueron: 
1.- América Latina hoy y el futuro de la educación, la política, lo social, lo económico, lo cultural, lo espiritual, y el humanismo

1.- Latin America today and the future of education, politics, social, economic, cultural, spiritual, and humanism

1.- América Latina hoje e o futuro da educação, a política, o social, o económico, o cultural, o espiritual, e o humanismo

1. La evaluación del desempeño profesional del docente no es una política de larga data y tradición en América Latina, y sobre ella no se ha acumulado suficiente experiencia teórica y práctica, como para que cualquier país de la región que decida implementar o perfeccionar una política de este tipo, pueda partir solamente de estudiar y aplicar los conocimientos acumulados en estos países.

2. Si bien existen disposiciones jurídicas que sustentan la aplicación de esa política educativa en 10 de los 14 países estudiados, en general, no se aplican consecuentemente en una parte importante de ellos.

3. Todavía existen sindicatos de educadores en países latinoamericanos, que mantienen una actitud de rechazo a la implementación de la evaluación del desempeño docente, lo que revela que queda mucho por hacer, para lograr que este tipo de acción tenga la viabilidad política que requiere.

4. Aún, en una parte importante los países estudiados, no es la observación directa de clases, el método principal que se utiliza para evaluar el desempeño de los maestros.

5. Los países del estudio no responden de la misma manera las preguntas, para qué, qué y cómo evaluar el desempeño de los profesores, lo que indica claramente que no existen estándares regionales de desempeño en esta región geográfica.

No existen apenas investigaciones sobre este tema en la región, por lo que resulta limitado el conocimiento científico que se ha acumulado al respecto en la región. 14

Es importante dedicarse a crear un modelo para evaluar el desempeño de los profesores, con la participación de ellos, por supuesto, y evitar los efectos secundarios que se pueden ocasionar al implementar una evaluación de este tipo y toda una serie de problemas éticos que pudieran surgir, no obstante, se considera que es una garantía para elevar la calidad de la educación en el área.

Ante la necesidad de elevar la calidad del proceso educativo se ha comenzado a implementar "modelos" evaluativos. Las investigaciones que

14 Valdés, H... Obra citada, pág. 29-30. 
1.- América Latina hoy y el futuro de la educación, la política, lo social, lo económico, lo cultural, lo espiritual, y el humanismo

1.- Latin America today and the future of education, politics, social, economic, cultural, spiritual, and humanism

1.- América Latina hoje e o futuro da educação, a política, o social, o económico, o cultural, o espiritual, e o humanismo

se han realizado arrojan, por lo menos, la existencia de cuatro modelos, a saber:

1. El modelo centrado en el perfil del profesor;

2. El modelo centrado en los resultados obtenidos;

3. El modelo centrado en el comportamiento del profesor en el aula;

4. El modelo de la práctica reflexiva o la reflexión en la acción.

En el caso del último "modelo" de referencia, se trata de una instancia de reflexión supervisada. Es, en definitiva, una evaluación para mejorar el personal académico y no de control que motive despidos o promociones.

En el desarrollo de los modelos de evaluación de los educadores, se descubren las influencias de las tendencias más señaladas en materia pedagógica en América Latina a inicios del s. XXI: el conductismo, el humanismo, el cognitivismo, el constructivismo y el enfoque históricoculturalista.

Las condiciones históricas concretas a inicios del nuevo milenio y, las necesidades objetivas de los diferentes países, imponen reconceptualizar la Pedagogía y la Didáctica y ofrecer el enfoque o tendencia que más satisfaga los intereses y necesidades de cada país. Se considera que la última palabra no está aún dicha en este aspecto.

\section{Algunas consideraciones sobre la calidad de la educación}

Ha existido una preocupación constante acerca de la educación y su calidad. Los servicios educativos llegan a todos los rincones del país y la escolarización es alta. No obstante, siempre existió preocupación y ocupación acerca de la calidad del resultado de la educación.

Existen, en la actualidad, grupos de trabajo dedicados a estudiar la calidad del proceso de enseñanza aprendizaje, para conocer científicamente las causas de las dificultades que se presentan y por supuesto, tomar las medidas y hacer los cambios que sean necesarios para eliminar esos problemas.

Por supuesto, que a lo largo de estos años se ha consolidado un grupo de especialistas acerca de la calidad de la educación, entre los que se 
1.- América Latina hoy y el futuro de la educación, la política, lo social, lo económico, lo cultural, lo espiritual, y el humanismo

1.- Latin America today and the future of education, politics, social, economic, cultural, spiritual, and humanism

1.- América Latina hoje e o futuro da educação, a política, o social, o económico, o cultural, o espiritual, e o humanismo

encuentra el doctor Héctor Valdés, que se ha cultivado en esta importante área del proceso educativo.

En la obra de su autoría: Calidad de la educación básica y su evaluación, ha definido que la calidad de la educación se refiere a las características del proceso y a los resultados de la formación y el desarrollo del hombre, condicionados histórica y socialmente, que toman una expresión concreta a partir de los paradigmas filosófico, pedagógico, psicológico y sociológico imperantes en la sociedad de que se trate.

Se ha perfeccionado toda una serie de herramientas para conocer el estado del proceso educativo en diferentes momentos del año escolar, no relacionado sólo con el aprendizaje propiamente dicho -contenidos conceptuales, procedimentales y actitudinales-, sino también y muy especialmente con los llamados "factores asociados" que inciden y a veces determinan los resultados esperados.

También se ha entendido que resulta muy importante conocer y perfeccionar la actividad del profesor para el logro de fines más amplios y formativos del individuo, por eso, se ha insistido mucho, además de otros factores, en la "evaluación" de la calidad del aprendizaje, pero vinculada a la "calidad del desempeño del profesor como profesional de la educación". Para ello, existen un modelo y una estrategia, diseñada por el doctor Valdés Veloz, que se aplican en el país y que constituyen su tesis de Doctor en Ciencias Pedagógica. Este modelo ha sido experimentado anteriormente y ha dado buenos resultados.

No es un secreto para nadie que algunos países Latinoamericanos, viven lo que se llama una "Tercera Revolución Educativa", que significó un cambio profundo en la extensión de los servicios educativos, pero también en su calidad.

Se aprecia una visión socio política totalizadora de la sociedad, y que esa es: la cultura. Por eso, se habla de la cultura integral para todos en el país, con este particular enfoque, se logrará el fin último ideológico-político de la colectividad. Con este objetivo, se busca la universalización de los conocimientos, que queda expresado en la universalización de la educación general y de la Universidad en particular, que se ha extendido por todo el país.

Es necesario que todas las instituciones y funcionarios de la sociedad desde cualquier parte en que estén, eduquen y para eso tienen que poseer cultura general integral y esta se alcanza por diferente vías: mesas 
1.- América Latina hoy y el futuro de la educación, la política, lo social, lo económico, lo cultural, lo espiritual, y el humanismo

1.- Latin America today and the future of education, politics, social, economic, cultural, spiritual, and humanism

1.- América Latina hoje e o futuro da educação, a política, o social, o económico, o cultural, o espiritual, e o humanismo

redondas informativas que actualizan a toda la población sobre los principales problemas nacionales e internacionales; a partir de la información que aparece en Internet y por otros medios, que ofrecen a la población diversos cursos de cultura general para lograr así los conocimientos en: ciencias, tecnología y humanidades que todo ser humano requiere para cumplir su misión educativa, como también otros programas, que amplían el mundo de la cultura.

En este sentido se cumple la expresión Martiana que: "Todo hombre al nacer tiene derecho a que se le eduque, pero después, en pago, contribuir a la educación de los demás". Esto no significa que cada hombre tenga que convertirse en un maestro de escuela, sino en un verdadero educador dondequiera que se encuentre, pues la educación es una responsabilidad de todos.

El proceso de los nuevos cambios educativos, que redundarán en la calidad de la educación está en marcha y su constante evaluación permitirá rectificar a tiempo los inconvenientes y profundizar en los logros.

Durante mucho tiempo, la deficiente cobertura y la baja calidad de la educación pública latinoamericana ha sido vista como una de las principales causas del lento crecimiento económico y de la desigualdad en la distribución del ingreso. A partir de la Segunda Guerra Mundial, muchos gobiernos decidieron contratar más maestros y construir nuevas escuelas; como consecuencia, a principios de los años ochenta, la mayoría de las niñas y niños en edad escolar había ingresado a los primeros grados de primaria y el analfabetismo en los adultos se había reducido del $34 \%$ al $13 \%$ (Puryear 1997, 4). Sin embargo, a pesar de estos esfuerzos, la calidad, eficiencia y equidad del servicio educativo permanecieron bajas. Las deficiencias en la calidad se vieron reflejadas en varios patrones problemáticos:

1. Los índices de repitencia y deserción fueron altos con relación al Producto Interno Bruto. A principio de los años noventa, uno de cada dos estudiantes repetía el primer grado y el promedio de la mano de obra urbana apenas alcanzaba cinco años de escolaridad, un nivel bastante bajo con respecto al alcanzado por países de mediano ingreso en otras regiones (IDB 1998, 45; Programa de Promoción de la Reforma Educativa de América Latina y el Caribe (PREAL) 2001, 8; Birdsall y Londoño 1998, 115). 
1.- América Latina hoy y el futuro de la educación, la política, lo social, lo económico, lo cultural, lo espiritual, y el humanismo

1.- Latin America today and the future of education, politics, social, economic, cultural, spiritual, and humanism

1.- América Latina hoje e o futuro da educação, a política, o social, o económico, o cultural, o espiritual, e o humanismo

2. Aun cuando las desigualdades de género se redujeron considerablemente en el período 1960-1990, hubo marcadas diferencias en otros niveles. Se mantuvieron grandes inequidades entre la población rural y la urbana, entre las regiones ricas y pobres de cada país y entre las diferentes categorías de ingresos. Entre los casos más favorables (Argentina y Uruguay), el $20 \%$ más rico de la población contaba con, aproximadamente, el doble de escolaridad que el $20 \%$ más pobre; en los casos menos favorables (Brasil y México), la proporción fue de 4 a 1 . Según datos del PREAL.

3. Las prioridades del gasto público favorecieron la educación superior, un patrón que reflejó las preferencias y el poder de influencia de mediano y alto ingreso, con posibilidades de enviar a sus hijos a escuelas privadas de primaria y secundarias (Birdsall, Londoño, y O'Connell 1998; Paul y Wolfe 2996).En Chile, Costa Rica, República Dominicana y Uruguay, la quinta parte más rica de la población recibió más del 50\% de los subsidios para educación superior, mientras que la quinta parte de los más pobres recibió apenas un 10\% (Banco Mundial, 79).

A principios de los años noventa un creciente número de economistas, analistas de políticas públicas, e instituciones internacionales de financiación, comenzaron a prestar atención a la necesidad de mejorar la calidad, equidad y eficiencia de la oferta educativa. Estas preocupaciones reflejaban antiguas convicciones de economistas, orientados hacia el mercado y preocupados por la importancia de invertir en el "capital humano", las cuales fueron reforzadas por la creciente brecha que existió entre las sociedades latinoamericanas y del Oriente Asiático, durante los años ochenta y noventa (Banco Mundial ,1993). En este documento se comprobaron diferentes casos y examinaron algunos de los factores que determinan las similitudes y diferencias entre países.

Es necesario señalar que muchos de las deficiencias en los sectores educativos de América Latina, son el producto de factores estructurales sobre los cuales los reformadores han tenido muy poca incidencia. La distribución desigual de activos e ingresos que caracteriza a la mayoría de las sociedades latinoamericanas, ha sido causa subyacente -al igual que efecto- de muchos de los problemas que se presentaron.

El alto sesgo en la distribución del ingreso ha aumentado la propensión de los grupos de altas rentas, a evadir impuestos destinados a la educación 
1.- América Latina hoy y el futuro de la educación, la política, lo social, lo económico, lo cultural, lo espiritual, y el humanismo

1.- Latin America today and the future of education, politics, social, economic, cultural, spiritual, and humanism

1.- América Latina hoje e o futuro da educação, a política, o social, o económico, o cultural, o espiritual, e o humanismo

pública, dejando a las familias ubicadas en las categorías de bajas retribuciones los costos de la educación. Las características del mercado laboral debilitaron, aún más, los incentivos para que las familias pobres mantuvieran a sus hijos en la escuela. El sector exportador de productos primarios en América Latina no ha requerido de un gran suministro de mano de obra calificada y las oportunidades de empleo en los sectores de sustitución de importaciones han sido limitadas. Por último, las bajas expectativas de retorno de la educación han contribuido a aumentar las tasas de deserción del nivel de educación primaria (Birsdsall y Londoño 1998).

Las deficiencias organizacionales y financieras de la oferta educativa también contribuyeron al déficit en calidad y al bajo desempeño. Gran parte de la crítica que surgió en los años ochenta y noventa estuvo dirigida hacia la excesiva centralización, rigidez organizacional e influencia en las jerarquías del sector educativo. Para ser precisos, no todos los sistemas escolares estaban totalmente centralizados al nivel nacional. Entre los países incluidos están Argentina, Brasil y Colombia, los gobiernos locales habían adquirido considerables responsabilidades financieras y administrativas al interior de los gobiernos federales. En México, Venezuela y Nicaragua las decisiones estaban mucho más centralizadas, aun cuando los sistemas locales coexistían con sistemas estatales en los dos primeros países.

A pesar de estas diferencias, los gobiernos centrales de todos estos países mantuvieron una significativa autoridad discrecional en temas, como la transferencia de fondos, provisión de libros de texto, material de enseñanza y currículo. Los sistemas escolares todavía se caracterizan por un bajo nivel de accountability (rendición de cuentas), poco espacio para la innovación y experimentación a nivel local, y escases de incentivos, los directores y profesores buscarán una mejoría en sus prácticas pedagógicas.

\section{Referencias bibliográficas}

Aguerrondo, I. (1993). Et Al. Para qué sirve la escuela. Grupo Editorial Norma. Bs. As. Argentina.

Castro, F. (1992) Mensaje a la Primera Cumbre Iberoamericana, Fondo de Cultura Económica. Guadalajara, México. 
1.- América Latina hoy y el futuro de la educación, la política, lo social, lo económico, lo cultural, lo espiritual, y el humanismo

1.- Latin America today and the future of education, politics, social, economic, cultural, spiritual, and humanism

1.- América Latina hoje e o futuro da educação, a política, o social, o económico, o cultural, o espiritual, e o humanismo

Castellanos, D. otros. (2001) Hacia una concepción del aprendizaje desarrollador. Colección Proyectos. ISP. Universidad Pedagógica Enrique José Varona. La Habana Cuba.

Cassasus, J. y otros. (2000). Primer estudio comparativo sobre Lenguaje y Matemática y factores asociados. UNESCO. Santiago de Chile.

CEPAL. (2014). Panorama fiscal de América Latina y el Caribe. Santiago de Chile.

De la Luz y Caballero, J. (1997) Aforismo. Selección de textos.

Gómez, H. y otros (1999). La educación del siglo XXI. Hacia un desarrollo humano. Tercer Mundo. Bogotá.

Fernández, M. (1992) Poder y participación en el sistema educativo. Paidós. Barcelona.

Fullat, O. (2000). Filosofía de la Educación. Editorial Paidós. Barcelona.

La Educación para Todos. Carpeta de Información. En: Un objetivo a nuestro alcance.

Martí, J. (1998) Obras completas. Centro de Estudios Martianos. La Habana, Cuba.

Mayoral, V. (1975) "La gestión democrática del sistema educativo". En: Documentación administrativa. Instituto Nacional de Administración Pública. INAP. España.

Moreno, L. (2011). La década de América y el Caribe, una oportunidad real. Banco Interamericano de Desarrollo (BID). Washington. USA.

Rojas. C. y D. Torres (2001). "El cambio educativo: una concepción avanzada para el mejoramiento de la calidad de la educación". En: Revista Varona, Ciudad de La Habana.

Valdés, H. (2015). Un sistema de evaluación del desempeño profesional del docente de escuela básica cubana. Tesis para optar por el grado científico de Doctor en Ciencias Pedagógicas.

Dra. Carmen Helena Bustamante Guerrero. Normalista Superior del Colegio Mayor de Cultura Femenino de Cundinamarca. Licenciada en Ciencias de la Educación con énfasis en Filosofía e Historia de la Universidad La Gran Colombia. Magíster en Lingüística y Literatura del Instituto Caro y Cuervo. Doctora en Ciencias Pedagógicas del Instituto Central de Ciencias Pedagógicas de la Habana (Cuba). Correo: juancepedah@gmail.com 